\title{
Ischaemic enterocolitis
}

\author{
V. J. McGOVERN AND S. J. M. GOULSTON \\ From the Fairfax Institute of Pathology and the A. W. Morrow \\ Department of Gastroenterology, Royal Prince Alfred Hospital, Sydney
}

EDITORIAL SYNOPSIS Ischaemic enterocolitis is often incorrectly called fulminant ulcerative colitis at necropsy and this paper sets out the evidence on which a correct diagnosis may be made. The condition may be precipitated by an episode of hypotension in a patient with some degree of bowel ischaemia, producing sudden hypoxia. Such hypotension imitating the disease reaction may be due to a variety of causes, such as the administration of hypotensive drugs, haemorrhage, or cardiac infarction.

In 1954 Wilson and Qualheim described 20 examples of a haemorrhagic enterocolitis affecting persons suffering from chronic illness, chiefly of the circulatory system. The disorder they described is quite distinct from any other form of enterocolitis, and was manifested by an abrupt onset of abdominal pain followed by diarrhoea, often of a bloody nature, and circulatory collapse. At necropsy they found mucosal oedema and haemorrhage with scattered shallow ulcers affecting a variable proportion of the entire intestinal tract.

The true incidence of this disorder is unknown because pathologists in the past have been inclined to regard it as 'terminal', 'agonal', 'uraemic', a form of pseudo-membranous enterocolitis, or even as a fulminant ulcerative colitis, while milder manifestations may be regarded as merely congestion unless examined histologically.

We have studied 33 examples of this type of enterocolitis encountered over a period of 14 years, and have been able to characterize it as a distinct clinico-pathological entity which we have labelled 'ischaemic enterocolitis' because vascular insufficiency of the bowel seems to predispose to it and it is often precipitated by hypotension.

\section{PATHOLOGY}

The main pathological findings are summarized in the Table. The small intestine was affected more severely than the large bowel in a few cases but the large bowel generally bore the brunt of the disorder and in many cases was unaccompanied by any small bowel involvement. The appearance of the bowel often suggested infarction, being darkly congested, sometimes dilated, with red oedematous mucosa.
Ulceration was superficial, linear or transverse, but occasionally deeper with extensive denudation and even perforation (Fig. 1). Perforations were found in five instances, three being of the small intestine. Peritonitis was occasionally observed even when there was no perforation and consisted of fibrinous

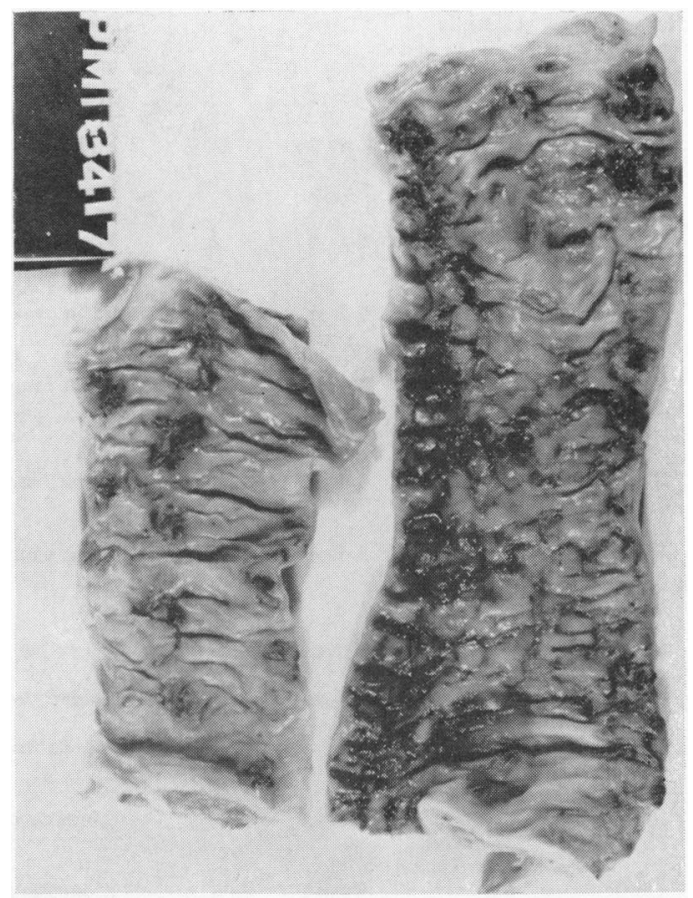

FIG. 1. Typical naked-eye appearance in ischaemic enterocolitis. Oedematous small bowel with patchy congestion and superficial ulceration. 
TABLE

SUMMARY OF CLINICAL AND PATHOLOGICAL FINDINGS

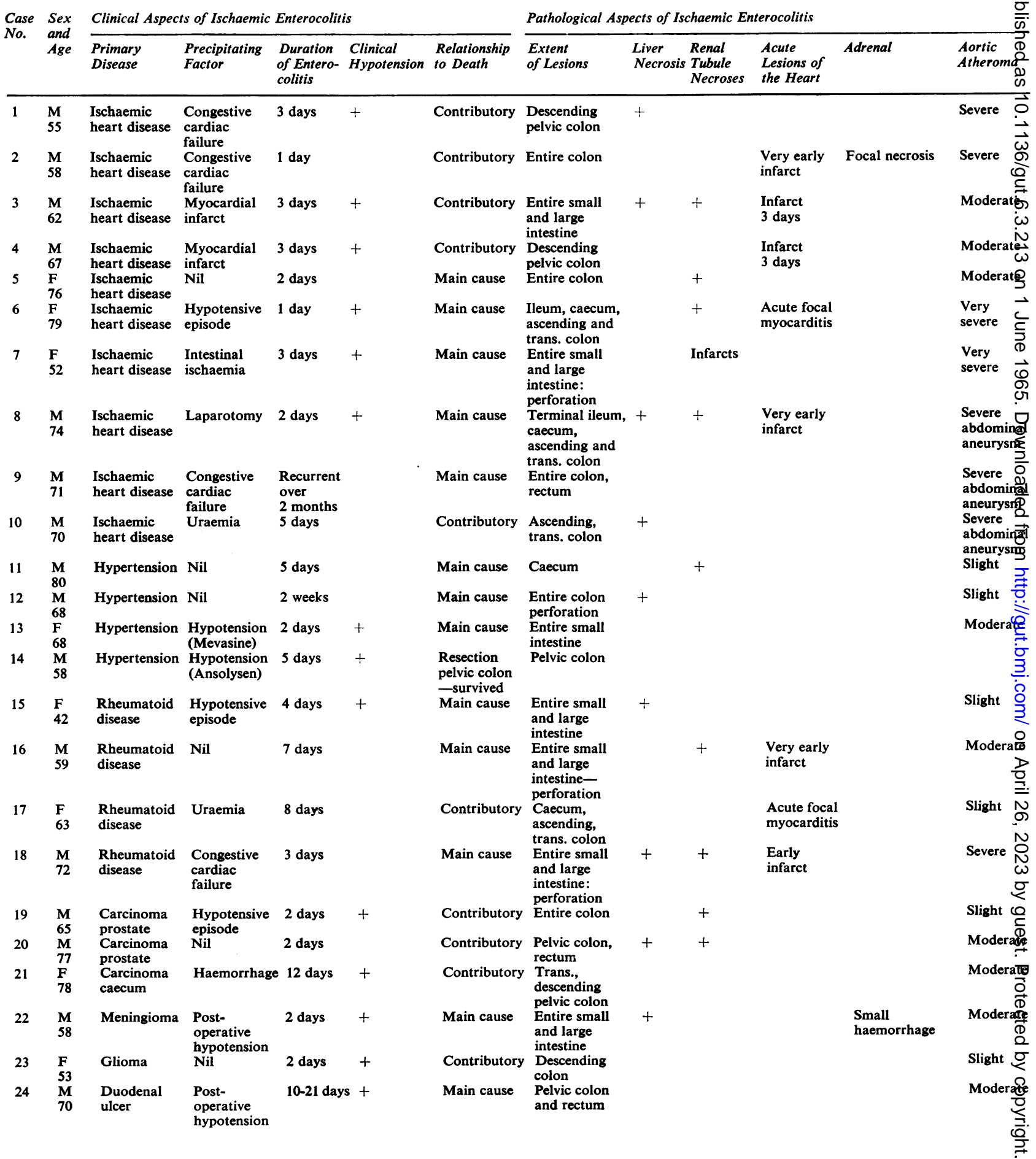


TABLE continued

SUMMARY OF CLINICAL AND PATHOLOGICAL FINDINGS

\begin{tabular}{|c|c|c|c|c|c|c|c|c|c|c|c|c|}
\hline \multirow{2}{*}{$\begin{array}{l}\text { Case } \\
\text { No. }\end{array}$} & \multirow{2}{*}{$\begin{array}{l}\text { Sex } \\
\text { and } \\
\text { Age }\end{array}$} & \multicolumn{5}{|c|}{ Clinical Aspects of Ischaemic Enterocolitis } & \multicolumn{6}{|c|}{ Pathological Aspects of Ischaemic Enterocolitis } \\
\hline & & $\begin{array}{l}\text { Primary } \\
\text { Disease }\end{array}$ & $\begin{array}{l}\text { Precipitating } \\
\text { Factor }\end{array}$ & $\begin{array}{l}\text { Duration } \\
\text { of Entero- } \\
\text { colitis }\end{array}$ & $\begin{array}{l}\text { Clinical } \\
\text { Hypotension }\end{array}$ & $\begin{array}{l}\text { Relationship } \\
\text { to Death }\end{array}$ & $\begin{array}{l}\text { Extent } \\
\text { of Lesions }\end{array}$ & $\begin{array}{l}\text { Liver } \\
\text { Necrosis }\end{array}$ & $\begin{array}{l}\text { Renal } \\
\text { Tubule } \\
\text { Necroses }\end{array}$ & $\begin{array}{l}\text { Acute } \\
\text { Lesions of } \\
\text { the Heart }\end{array}$ & Adrenal & $\begin{array}{l}\text { Aortic } \\
\text { Atheroma }\end{array}$ \\
\hline 25 & $\begin{array}{l}\mathbf{M} \\
53\end{array}$ & Gastric ulcer & $\begin{array}{l}\text { Post- } \\
\text { operative } \\
\text { hypotension }\end{array}$ & 2 days & + & Main cause & $\begin{array}{l}\text { Trans., } \\
\text { descending } \\
\text { colon }\end{array}$ & + & + & & & Moderate \\
\hline 26 & $\begin{array}{l}M \\
60\end{array}$ & $\begin{array}{l}\text { Chronic } \\
\text { bronchitis, } \\
\text { emphysema }\end{array}$ & $\begin{array}{l}\text { Hypotensive } \\
\text { episode }\end{array}$ & 2 days & + & Contributory & Pelvic colon & & & $\begin{array}{l}\text { Acute focal } \\
\text { myocarditis }\end{array}$ & & Severe \\
\hline 27 & $\begin{array}{l}M \\
63\end{array}$ & $\begin{array}{l}\text { Chronic } \\
\text { bronchitis, } \\
\text { emphysema }\end{array}$ & Hypoxia & 4 days & & Contributory & $\begin{array}{l}\text { Ileum, caecum, } \\
\text { ascending, trans. } \\
\text { colon }\end{array}$ & & & & & Severe \\
\hline 28 & $\begin{array}{l}\text { M } \\
80\end{array}$ & $\begin{array}{l}\text { Acute } \\
\text { pancreatitis }\end{array}$ & $\begin{array}{l}\text { Adrenal } \\
\text { haemorrhage }\end{array}$ & 4 days & + & Contributory & Pelvic colon & + & + & $\begin{array}{l}\text { Atrial } \\
\text { necrosis }\end{array}$ & Haemorrhage & Severe \\
\hline 29 & $\begin{array}{l}F \\
80\end{array}$ & $\begin{array}{l}\text { Liver } \\
\text { abscess }\end{array}$ & Nil & 2 days & & Contributory & $\begin{array}{l}\text { Descending } \\
\text { pelvic colon } \\
\text { and rectum }\end{array}$ & & & & & Severe \\
\hline 30 & $\begin{array}{l}F \\
69\end{array}$ & Diabetes & $\begin{array}{l}\text { Pulmonary } \\
\text { infarct }\end{array}$ & 2 days & & Contributory & $\begin{array}{l}\text { Descending } \\
\text { colon }\end{array}$ & & & & & Severe \\
\hline 31 & $\begin{array}{l}M \\
64\end{array}$ & $\begin{array}{l}\text { Aortic } \\
\text { incompetence }\end{array}$ & $\begin{array}{l}\text { Congestive } \\
\text { cardiac } \\
\text { failure }\end{array}$ & 2 days & + & Main cause & $\begin{array}{l}\text { Terminal } \\
\text { ileum, trans. } \\
\text { colon }\end{array}$ & + & + & & & Slight \\
\hline 32 & $\begin{array}{l}F \\
70\end{array}$ & $\begin{array}{l}\text { Femoral } \\
\text { hernia }\end{array}$ & $\begin{array}{l}\text { Intestinal } \\
\text { incarceration }\end{array}$ & 4 days & & $\begin{array}{l}\text { Resection } \\
\text { ileal segment } \\
\text { - survived }\end{array}$ & $\begin{array}{l}\text { Small segment } \\
\text { of ileum }\end{array}$ & & & & & \\
\hline 33 & $\begin{array}{l}F \\
67\end{array}$ & Nil & Nil & 1 day & + & Main cause & Entire colon & & & & & Slight \\
\hline
\end{tabular}

exudate on the surface of the bowel with a variable amount of bloodstained free fluid.

Microscopically the main features of ischaemic enterocolitis were haemorrhage into the mucosa and in severe cases into the submucosa, thromboses of mucosal capillaries and phlebitis of submucosal vessels, moderate leucocytic infiltration, and necrosis of the mucosa followed by ulceration. The earliest lesion was seen in the mucosa and consisted of a variable amount of haemorrhage, a light infiltrate of leucocytes and fibrin thrombi, with or without necrosis of the mucosal vessels (Fig. 2). Thrombi and mucosal haemorrhages constituted the main criteria for diagnosis of this type of enterocolitis. Oedema of the submucosa was often prominent but not invariably present. As the disorder progressed the mucosal thrombi extended into the submucosal venules which often exhibited acute inflammatory reaction or even necrosis as well as thrombosis. These vascular alterations seldom extended into the deep submucosal vessels (Figs. 3-7). Necrosis of the mucosa was followed by ulceration and at this stage leucocytic infiltration'became more pronounced. As in necrotizing colitis, colonies of bacteria were frequently observed in necrotic mucosa.

In 18 of the 33 cases there were zonal necroses of the liver and/or focal tubular necroses in the kidney of the type seen in hypotension (Fig. 8). There were other lesions also which might have resulted from hypotension, such as early myocardial infarction, and adrenal infarction (Table I). In addition there

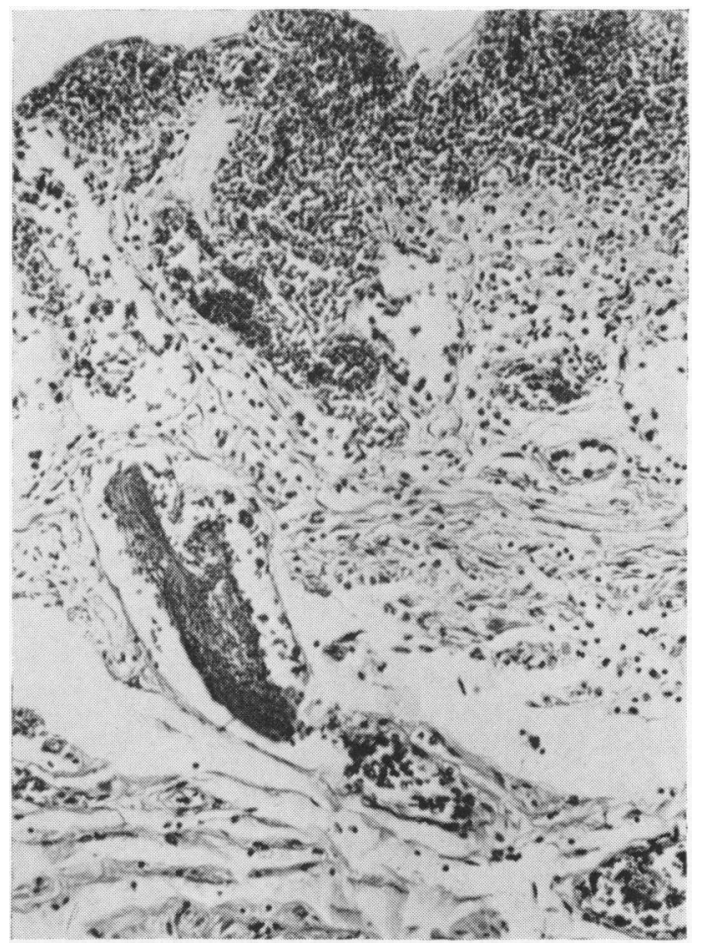

FIG. 2. Earliest lesion in ischaemic enterocolitis featuring haemorrhage into the superficial part of the mucosa, a fibrin thrombus in the deeper part, and scattered leucocytes. Haematoxylin and eosin $\times 150$. 


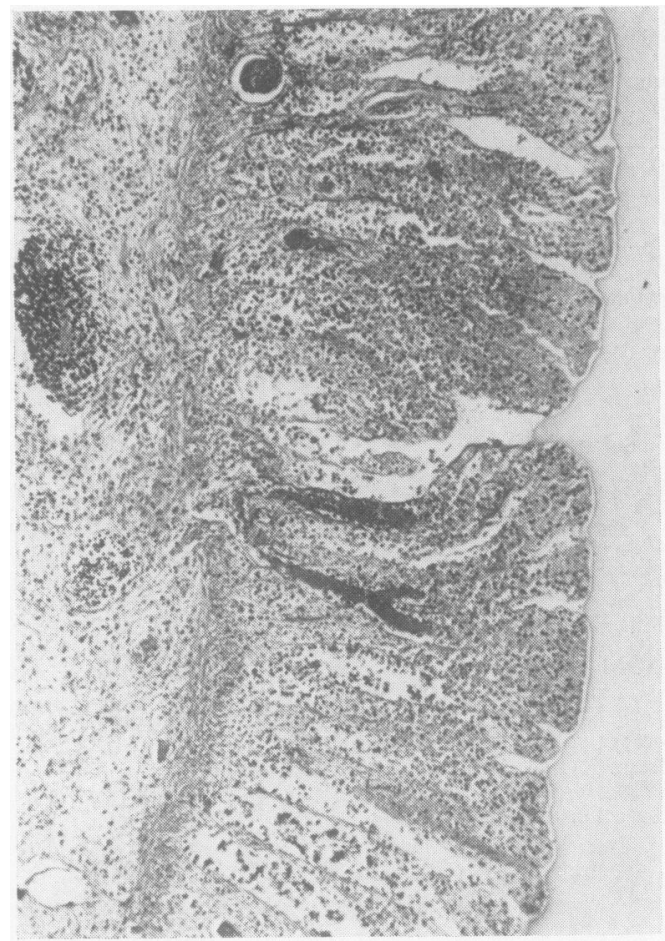

FIG. 3.

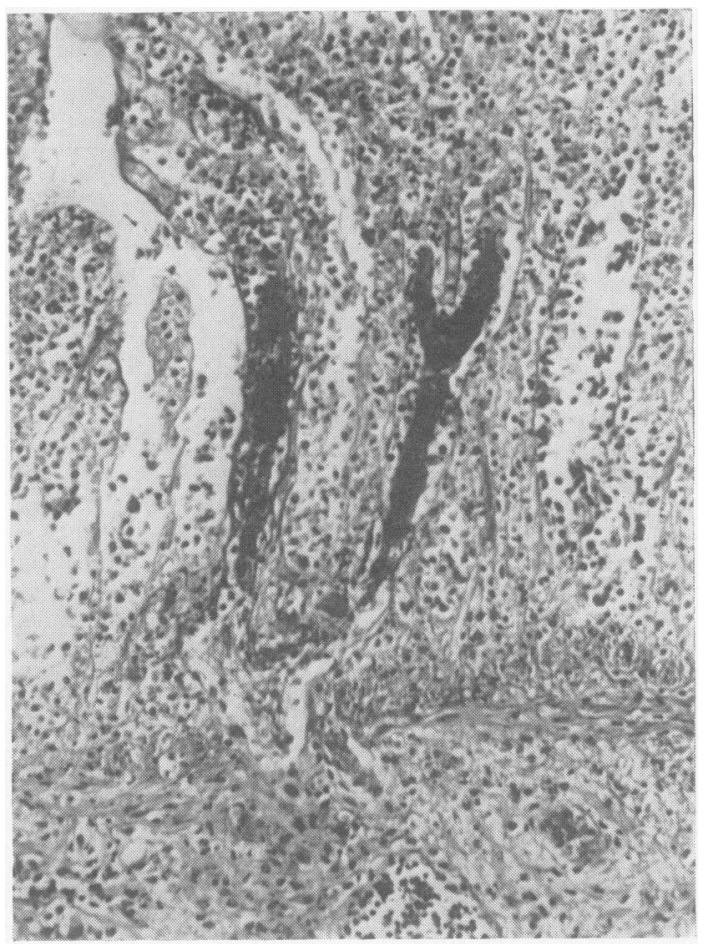

FIG. 4.

FIG. 3. Mucosal tubules are no longer recognizable, partly due to post-mortem change. There are numerous thrombi in the mucosa and a moderate inflammatory infiltrate. Haemorrhages are not prominent in this field. Haematoxylin and eosin $\times 75$.

FIG. 4. Higher-power of portion of mucosa illustrated in Fig. 3 to show fibrin thrombi. Haematoxylin and eosin.

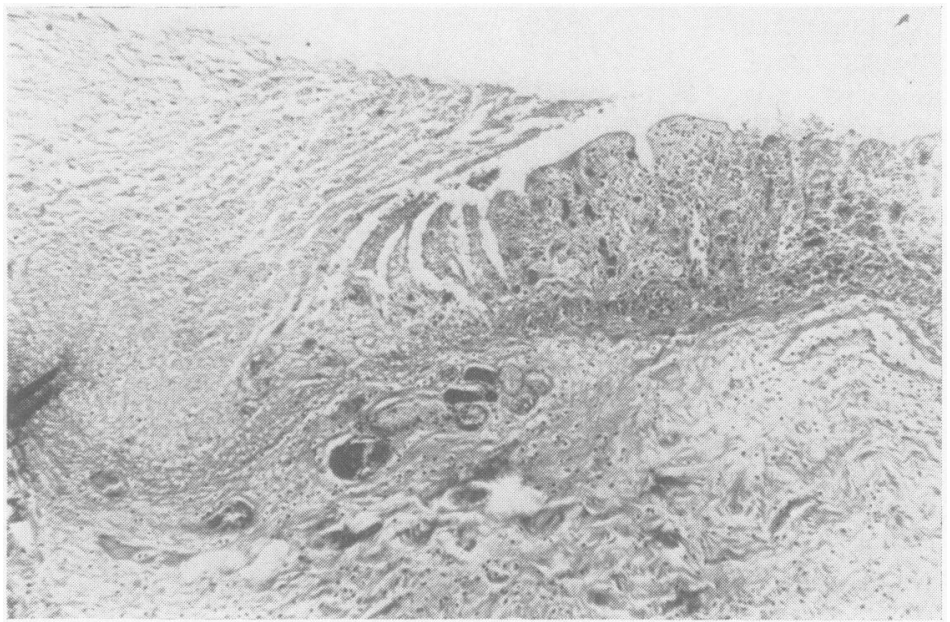

FIG. 5. Abrupt transition between necrotic mucosa and mucosa containing fibrin thrombi. Haematoxylin and eosin $\times 44$.

FIG. 5 . 


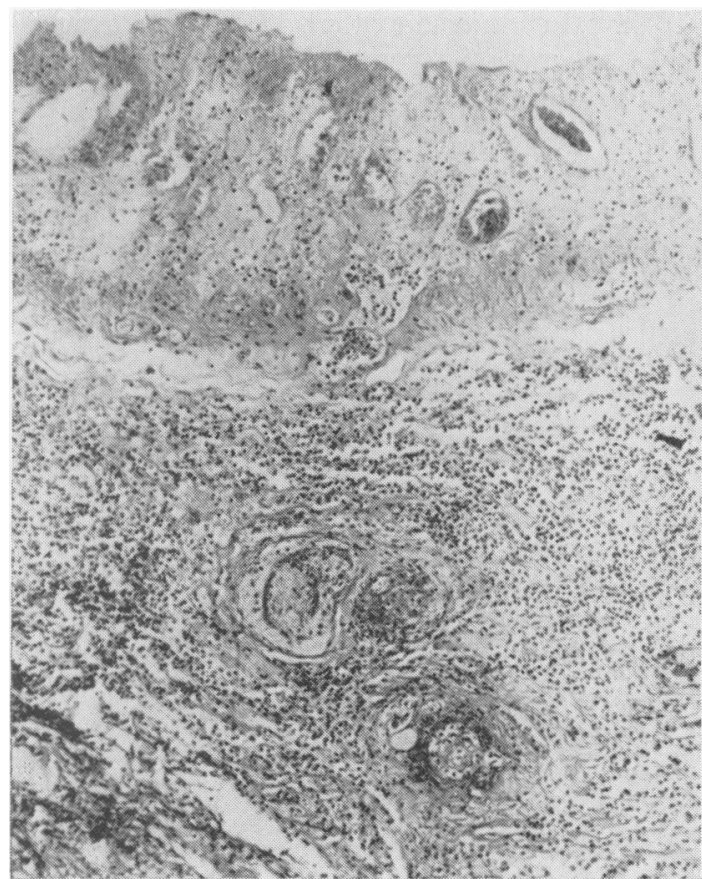

FIG. 6.

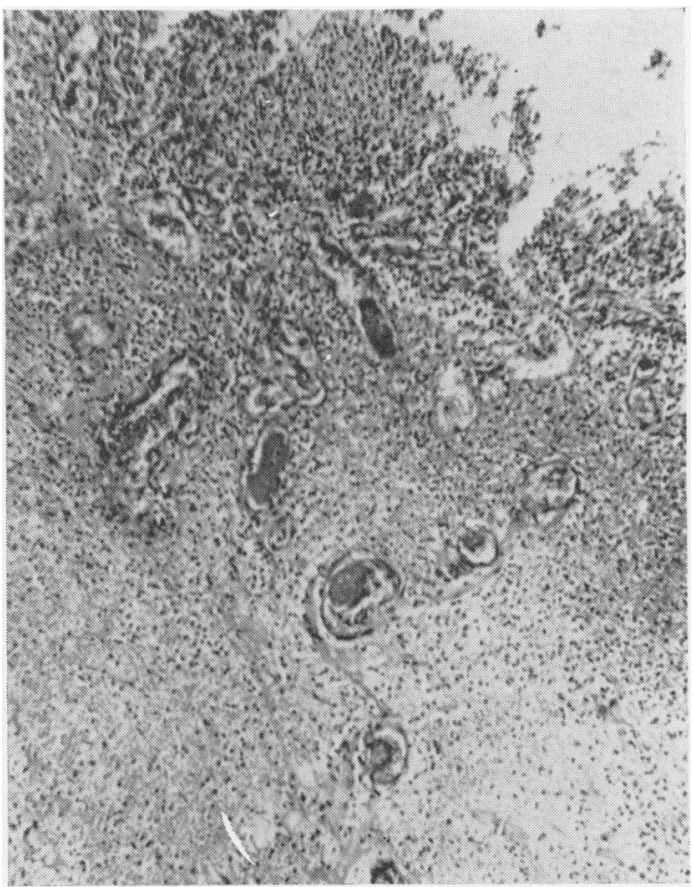

FIG. 7 .

FIG. 6. Necrosis of mucosa has occurred. There is an acute phlebitis and an acute inflammatory infiltrate in the submucosa. Haematoxylin and eosin $\times 75$.

FIG. 7. The affected portion of the incarcerated segment of ileum has ulceration of the mucosal surface in case 32. Vessels extending from the mucosa into the submucosa contain fibrin thrombi. The submucosa is oedematous and has an inflammatory infiltrate. Haematoxylin and eosin $\times 75$.

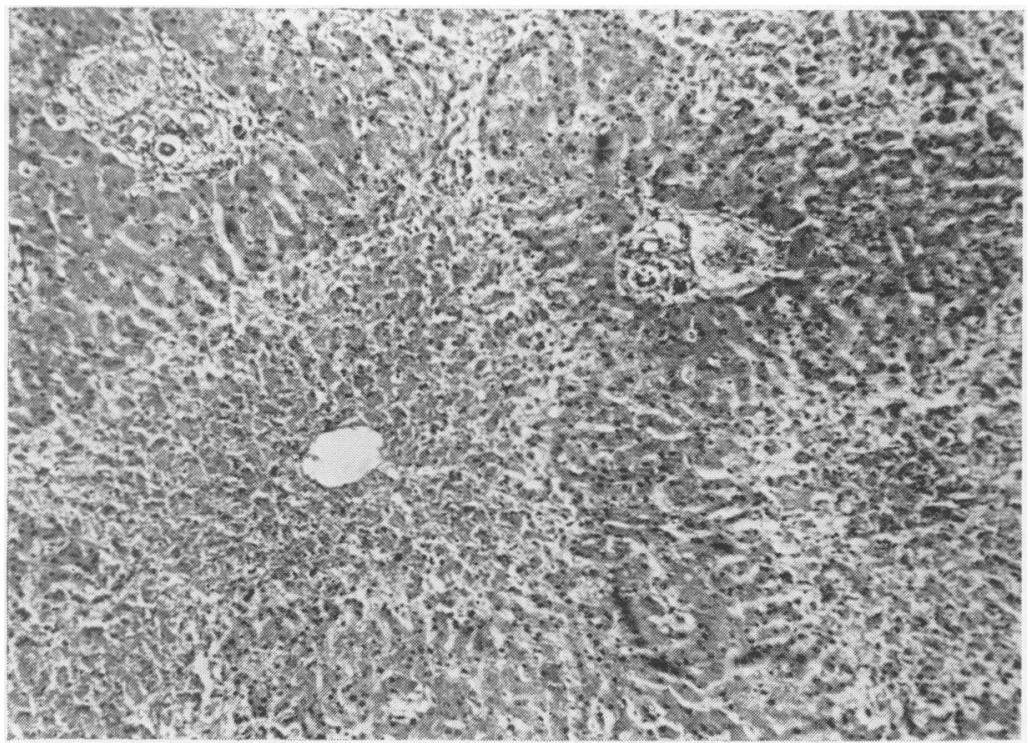

FIG. 8. Severe hypotensive necrosis of the liver in a patient with hypotension following myocardial infarction. Haematoxylin and eosin $\times 75$

FIG. 8. 
were three examples of acute focal myocarditis and one of very recent focal necrosis in the cardiac atrium.

Atherosclerosis of the abdominal aorta of severe degree was recorded in 23 necropsies but was of insignificant degree in eight. Of 10 patients who were being treated for ischaemic heart disease when enterocolitis supervened, six had symptoms of ischaemic bowel disease, and at necropsy all had severe atheroma of the abdominal aorta with aneurysm in three.

\section{CLINICAL FACTORS}

The main clinical aspects of this disorder are also summarized in the Table. The majority of patients were in the older age groups, 24 patients in the seventh, eighth, or ninth decades, and eight in the sixth decade. The youngest was a man aged 42 years suffering from rheumatoid arthritis. Males predominated in the proportion of 21 to 12 females.

In all cases except one a primary disease was present. Chronic cardiac disease accounted for 14 and rheumatoid disease for four. Four were postoperative, carcinoma was present in three, chronic lung disease in two, and liver abscess, intracranial tumour, and acute pancreatitis in one each. Six of the patients with chronic heart disease complained of abdominal pain after meals which was suggestive of mesenteric angina (cases 5 to 10 inclusive). Two hypertensive patients suffered hypotensive episodes when taking Ansolysen and Mevasine respectively. In each case this was followed by severe diarrhoea and abdominal pain. One of these patients died directly as a result of ischaemic enteritis involving the entire small bowel (case 14). The post-operative cases are of some interest, as this form of enterocolitis, which either caused or contributed to death, is rarely mentioned as a complication of surgery. The operations performed were partial gastrectomy for gastric ulcer, gastroenterostomy for duodenal ulcer, exploratory laparotomy for aortic aneurysm, and craniotomy for meningioma.

Precipitating factors were found to be congestive heart failure, myocardial infarction, pulmonary infarction, operation, uraemia, and blood loss. Clinical hypotension was recorded in 17 patients.

Of the 33 patients, two were operated upon with resection of the pelvic colon in one and an ileal segment in the other, and both survived. There were 31 deaths, and in these cases it was estimated that the ischaemic enterocolitis was the cause of death in 16 and contributed to death in 15 others.

The duration of the enterocolitis was measured in days, the majority of episodes ranging from one to
10 days. In one instance the symptoms were recurrent over a two-month period. The outstanding clinical feature was the onset of diarrhoea, generally sudden and following an episode of hypotension. Abdominal pain and the presence of bloody motions were infrequent.

The following three case histories are typical of the whole group.

\section{TYPICAL CASE HISTORIES}

CASE 3 A man aged 62 years was admitted to hospital with evidence of congestive cardiac failure, hypertension, and atrial fibrillation. The following day he developed sudden chest pain and a transient fall in blood pressure. He was considered to have had a pulmonary infarction but there was no radiological or electrocardiographic confirmation. He was heparinized and responded for the next two days. However, on the sixth day he suddenly collapsed and died. Necropsy revealed ischaemic heart disease with a recent coronary thrombosis and myocardial infarction. Ischaemic enterocolitis was present involving the entire small and large bowel.

CASE 24 A man aged 70 years had been treated by his local practitioner for some months for abdominal pains for which radiological studies had not provided a diagnosis. His blood pressure was recorded as 230 systolic, 130 diastolic. He was admitted to hospital after having a haematemesis and melaena. On admission his blood pressure was 95 systolic, 40 diastolic. Despite transfusions, bleeding from the alimentary tract continued and he was submitted to surgery that day. A large duodenal ulcer was excised and an anterior gastro-enterostomy performed. His post-operative course was unsettled with general abdominal discomfort and loose motions. After 19 days post-operatively he began vomiting and passed loose watery stools and became distended. He developed peripheral vascular failure and died three weeks after operation. At necropsy the pelvic colon and rectum were greatly dilated. The microscopic appearances were typical of severe ischaemic colitis. The small intestine was normal. Severe aortic atheroma was present.

CASE 26 A man aged 60 years had a long history of chronic pyelonephritis and emphysema. He suffered from an intermittent dysphagia for one week and for this a barium swallow was recommended. While this was being performed he had a sudden syncope with a fall in blood pressure but recovered quite rapidly. During the next four hours his heart rate remained at 120 per minute and a blood pressure of 90 systolic, 60 diastolic. An electrocardiogram showed sinus tachycardia only. During the next 24 hours his general condition deteriorated. He developed severe diarrhoea which continued until his death 48 hours after the radiological examination. At necropsy advanced atheroma of the aorta was found with chronic vesicular emphysema and chronic pyelonephritis. No occlusion of the coronary lumina was present. A severe ischaemic colitis involving the pelvic colon was found. 


\section{DISCUSSION}

DIFFERENTIAL PATHOLOGY Ischaemic enterocolitis is an entity which can be distinguished from other necrotizing condition of the intestines.

Acute colitis necroticans This, first described in Germany (von Meyenburg and Bosch-Gwalter, 1954) and since then by Killingback and Williams (1961), is a gangrenous condition of the bowel, usually affecting a segment of colon but occasionally affecting the small intestine, possibly due to $\mathrm{Cl}$. welchii toxin. The peritoneal cavity may contain large amounts of foul-smelling fluid and the affected portions of intestine have a greenish yellow necrotic appearance without any vascular obstruction. The wall of the gut is oedematous and in the early stages the mucosal surface is smooth, though later ulceration occurs. Microscopically, there is coagulative necrosis both of the mucosa and of a variable amount of submucosa. Leucocytes are usually numerous at the junction of necrotic and viable zones. Colonies of Gram-positive bacteria can be seen in the necrotic mucosa and if the submucosa has participated in the process they can be seen in it also, even within blood vessels.

Pseudo-membranous enterocolitis This mainly affects the colon though the small intestine can be involved sometimes even without any colonic lesion. To the naked eye there is a raised yellowish membrane sometimes confluent but often in small patches with quite normal bowel between. The mucosal surface undergoes fibrinoid necrosis with exudation of fibrin while at the same time there is hypersecretion of mucus by the underlying tubules. The fibrin, mucus and necrotic mucosa fuse to form a membrane in which leucocytes are scanty. Gradually the necrotizing process extends deeper into the mucosa and ulceration occurs if the membrane is discarded or undergoes dissolution (Goulston and McGovern, 1965).

Acute angiitis Acute angiitis, affecting vessels in the submucosa occasionally extending through the muscle coats to the serosa, may occur in rheumatoid arthritis and sometimes without any obvious cause. Generally only some of the segments of the alimentary tract are involved and in our experience angiitis has been confined to the caecum, transverse colon, or other short segments of gut. There is marked oedema of the submucosa with necrosis of arterioles followed by necrosis of the overlying mucosa and prominent leucocytic infiltration. One can be sure of this entity by observing that the arteriolitis precedes necrosis of the mucosa. In ischaemic enterocolitis the angiitis is confined to venules situated in the more superficial parts of the submucosa while in acute angiitis the affected vessels are arterioles which extend through the muscle coat. Thromboses are common in the ischaemic disease but rare in acute arteriolitis.

Suppurative enterocolitis To the naked eye this is characterized by the presence of pus with abscess formation in the mucosa and submucosa.

Ischaemic enterocolitis at necropsy is often wrongly labelled 'fulminant ulcerative colitis', but the pathological picture is quite different. In fulminant ulcerative colitis there is initially intense congestion and oedema of the submucosa. Ulceraation commences in the stretched mucosa overlying the taeniae where the submucosa is thinnest and undermines the adjacent mucosa. Similarly transverse ulceration occurs in the troughs of the rugae and in this way a good deal of mucosa can be shed leaving intact mucosal tags that will form pseudopolyps. Vascular necroses and thromboses are not a feature of ulcerative colitis. The ulceration of the fulminant disease always extends into the submucosa, often to the muscularis. In less acute forms of ulcerative colitis congestion and oedema of the mucosa and submucosa are followed by the formation of crypt abscesses which rupture into the lamina propria and occasionally into the submucosa. By extending laterally the mucosa is undermined and shed, giving rise to superficial ulceration (McGovern and Archer, 1957; McGovern, 1963).

PATHOGENESIS The two main features in the pathogenesis of the enterocolitis studied in this paper are bowel ischaemia and hypotension. As Marston (1962) pointed out, pre-existing ischaemia of the bowel in older age groups is an important cause of death following hypotension however caused. Unfortunately he makes no clear distinction between pseudo-membranous enterocolitis, acute colitis necroticans, and the disorder under discussion. We agree with Marston that hypotension plays an important part in initiating the process of enterocolitis and must emphasize that persons with no pre-existing occlusive vascular disease may be affected, though less commonly than those who have atheromatous obstruction of the superior mesenteric and coeliac axis arteries. Whether there was ischaemic disease of the bowel or not, the onset of enterocolitis was always sudden and in many cases was preceded by clinically observed hypotension.

Chronic ischaemia causes atrophy and thinning of the gut wall and its mucosa but the onset of enterocolitis is always abrupt even in emaciated patients with long-standing symptoms of bowel ischaemia. That sudden incomplete ischaemia is the important factor is illustrated in case 32, a woman of 70 years with a short segment of ileum incarcerated in a femoral hernia. The affected segment was 
very dark, congested, and oedematous with ulceration of its mucosa. To the naked eye it appeared gangrenous but histologically the appearance was typical of ischaemic enteritis with a prominent polymorphonuclear leucocytic infiltration throughout all coats and fibrin thrombi in the unulcerated mucosa and in submucosal venules (Fig. 7). The patient made a complete recovery after resection. Vascular obstruction must have been incomplete and sufficient blood flow must have continued for the inflammatory reaction to take place.

The main cause of sudden ischaemia in this series was hypotension which preceded the onset of bowel symptoms in 19 of the 33 cases. In most of the others the condition of the patient suggested the likelihood of such a state, as for example, the onset of congestive cardiac failure. In another seven in whom no clinical hypotension was recorded apart from that in the agonal period, there was histological evidence in the liver and/or kidney, consisting of zonal necrosis in the liver and small foci of necrosis of proximal tubular epithelium in the kidney.

The ischaemic bowel can be compared to the ischaemic heart. In each there may be a period of angina culminating in a sudden acute illness, enterocolitis on the one hand, infarction on the other. Hypotension alone can cause myocardial infarction and this has been observed amongst our cases of enterocolitis also. Myocardial infarction has an inflammatory component and similarly there is an inflammatory reaction in the bowel condition indicating that there is sufficient circulation to maintain a supply of leucocytes to the affected area. From the above facts it seems most likely that sudden hypoxia, whether there has been pre-existent chronic ischaemia or not, is the most likely precipitating factor.

The effect of bacterial toxins upon ischaemic bowel mucosa is unknown but the possibility that toxins act directly upon the bowel mucosa or through a Shwartzman type reaction must be considered. Experimentally a counterpart of the human condition can be found in the work of Anderson and Brunson (1959) who induced a state of shock in rabbits. Surviving animals exhibited changes in the small bowel that varied from acute congestion of the gut with intraluminal haemorrhages to the extensive thrombosis of mucosal vessels associated with areas of necrosis. An intravenous injection of $E$. coli endotoxin greatly intensified all these phenomena. The resemblance between the experimental disorder of rabbits and the natural disorder of a man is further accentuated by the fact that hypotension seems to be a precipitating factor in each. It has been shown by Thomas (1956) and by Zweifach, Nagler, and Thomas (1956) that endotoxin alters the reactivity of animal tissues to catechol amines which thereupon become potent necrotizing agents. If this mechanism pertains in humans, one would have to postulate an increase both in natural catechol amines and in endotoxin within the bowel.

One can only conclude that sudden hypoxia may initiate ischaemic enterocolitis and that persons with atherosclerotic vascular disease are particularly likely to be affected, especially if they have already some degree of bowel ischaemia. This hypoxia may result from an attack of hypotension due to a variety of disorders, including the administration of anti-hypertensive drugs. The patchy nature of the condition suggests that in addition to hypoxia, local factors play some part, but whether through bacterial action of some other mechanism is undetermined.

\section{REFERENCES}

Anderson, J. M., and Brunson, J. G. (1959). The influence of acute stress on the response of rabbits to intravenous endotoxin. Circulat. Res., 7, 37-43.

Goulston, S. J. M., and McGovern, V. J. (1965). Pseudo-membranous colitis. Gut, 6, preceding Paper.

Killingback, M. J., and Williams, K. L. (1961). Necrotizing colitis. Brit. J. Surg., 49, 175-185.

McGovern, V. J. (1963). The pathology of ulcerative colitis. J. Coll. Radiol. Aust., 7, 168-170.

Aust. Ann. Med., 6, 68-74.

Marston, A. (1962). The bowel in shock. The role of mesenteric arterial disease as a cause of death in the elderly. Lancet, 2, 365-370.

Meyenberg, H. von, and Bosch-Gwalter, T. (1954). Enteritis necrotica. In The Year Book of Pathology and Clinical Pathology (19531954 series), edited by W. B. Wartman, pp. 155-156. Chicago, Year Book Publishers.

Thomas, L. (1956). The role of epinephrine in the reactions produced by the endotoxins of gram-negative bacteria. I. Hemorrhagic necrosis produced by epinephrine in the skin of endotoxintreated rabbits. J. exp. Med., 104, 865-880.

Wilson, R., and Qualheim, R. E. (1954). A form of acute hemorrhagic enterocolitis afficting chronically ill individuals. Gastroenterology, 27, 431-444.

Zweifach, B. W., Nagler, A. L., and Thomas, L. (1956). The role of epinephrine in the reactions produced by the endotoxins of gram-negative bacteria. II. The changes produced by endotoxin in the vascular reactivity to epinephrine, in the rat mesoappendix and the isolated, perfused rabbit ear. J. exp. Med., 104, 881-896. 